\title{
Fragility fractures of the spine
}

\author{
Oliver Gonschorek $^{1} \cdot$ Marius Keel $^{2}$
}

Received: 7 December 2016 / Accepted: 21 December 2016 / Published online: 11 January 2017

(C) Springer-Verlag Berlin Heidelberg 2017

The number of the elderly population in the industrial countries has been growing over the last decades and will continuously be growing in the future. Reduced bone quality leads to rising numbers of fragility fractures. The treatment principles are varying and despite a huge number of literature optimal treatment algorithms remain controversial. Modern conservative treatment includes early mobilization and pain relief; radiological controls are important. If surgery is indicated, one can choose from a large pool of treatment options: cement augmentation alone, combined with stents or inserted after preparation of the vertebra by balloons or similar expanding techniques. Modern cements have been developed with optimized viscosity [1]. For unstable situations instrumentation may be indicated. In these cases the screws may be used cement augmented. This technique may also be advantageous for revision operations. In some cases combined posterior and anterior fusion may be indicated also in the elderly population resulting in challenging situations and possible higher complication rates. The Section Spine of the German Society of Orthopedics and Trauma Surgery (DGOU) has recognized the importance of the fragility fractures on the spine and founded a task force searching for new classifications and treatment algorithms [2].

Oliver Gonschorek

oliver.gonschorek@bgu-murnau.de

Marius Keel

marius.keel@insel.ch

1 Department of Spine Surgery, BGU Trauma Center, Murnau, Germany

2 Department of Orthopedic and Trauma Surgery, Inselspital, University Hospital, University of Bern, Bern, Switzerland
This special issue of the EJTES gives you insight into current and innovative treatment options for fragility fractures of the spine. In the first article Slavici et al. give an update on the conservative treatment of osteoporotic vertebral fractures, they analysed the pertinent literature extensively and present their preferred course of treatment [3]. Gonschorek et al. report upon cement augmentation with and without balloons and the limitations of current classifications for the special focus on osteoporotic fractures in the elderly [4]. Hoppe et al. then present indications and techniques, but also limitations for pedicle screw augmentation in osteoporotic spine. They describe this technique also for revision cases [5]. Finally, Spiegl et al. discuss indications, techniques and limitations of $360^{\circ}$ stabilizations in patients with osteoporotic fractures [6].

\section{Compliance with Ethical Standards}

The authors comply with the ethical guidelines for authorship and publishing in the European Journal of Trauma and Emergency Surgery. This article does not contain any studies with human or animal subjects performed by the authors.

Conflict of interest Oliver Gonschorek and Marius Keel declare no conflict of interest in relation to this work.

\section{References}

1. Benneker LM, Hoppe S. Percutaneous cement augmentation techniques for osteoporotic spinal fractures. Eur J Trauma Emerg Surg. 2013;39:445-453.

2. Blattert TR, Schnake KJ, Gonschorek O, The Working Group Osteoporotic Fractures of the German Trauma Society. Guidelines for non-surgical and surgical management of osteoporotic vertebral body fractures. Eur Spine J. 2015;24:S703.

3. Slavici A, Rauschmann M, Fleege C. Conservative management of osteoporotic vertebral fractures: an update. Eur J Trauma Emerg Surg. 2016. doi:10.1007/s00068-016-0747-5. 
4. Gonschorek O, Hauck S, Weiß T, Bühren V. Percutaneous vertebral augmentation in fragility fractures-indications and limitations. Eur J Trauma Emerg Surg. 2017. doi:10.1007/ s00068-016-0753-7.

5. Hoppe S, Keel MJB. Pedicle screw augmentation in osteoporotic spine: indications, limitations and technical aspects. Eur $\mathbf{J}$ Trauma Emerg Surg. 2016. doi:10.1007/s00068-016-0750-x.
6. Spiegl UJ, Jarvers J-S, Heyde C-E, Josten C. Osteoporotic vertebral body fractures of the thoracolumbar spine-indications and techniques of a $360^{\circ}$-stabilization. Eur J Trauma Emerg Surg. 2017. doi:10.1007/s00068-016-0751-9. 